\title{
Pyroelectricity of Benzene Derivates. II. Metanitrochlorobenzene, Paranitrobenzonitrile, and Parabromobenzonitrile
}

\author{
Silvia Fleck* and Alarich Weiss \\ Institut für Physikalische Chemie, Physikalische Chemie III, \\ Technische Hochschule Darmstadt, Darmstadt, West Germany
}

Z. Naturforsch. 42 a, 645-654 (1987); received March 11, 1987

\begin{abstract}
The pyroelectric properties of the benzene derivatives, 1-Cl-3- $\mathrm{NO}_{2}-\mathrm{C}_{6} \mathrm{H}_{4}, 1-\mathrm{CN}-4-\mathrm{NO}_{2}-\mathrm{C}_{6} \mathrm{H}_{4}$, and $1-\mathrm{CN}-4-\mathrm{Br}-\mathrm{C}_{6} \mathrm{H}_{4}$, were investigated in the temperature range $100 \leqq T / \mathrm{K} \leqq$ decomposition temperature. Dielectric measurements of single crystals of these compounds were performed. By use of a semiempirical quantum chemical model, including a point charge model of the solid matrix, the charge distributions in the molecules are calculated. With the therefrom resulting dipole moment and properties of a polar dielectric the change of the pyroelectric coefficient $\boldsymbol{p}$ with temperature is calculated. The experiments and calculations are discussed in connection with the known crystal structures of the substances.
\end{abstract}

\section{Introduction}

Polar crystals showing very large pyroelectric coefficients are found as well among inorganic solids as organic salts. Strong polarizability and/or hydrogen bonds within these classes of solids can be of advantage for strong pyroelectricity.

There is a third class of solids which deserves attention with respect to the phenomenon of pyroelectricity. This comprises organic molecular crystals, particularly benzene derivatives, composed of molecules which crystallize in a polar crystal class and may have an easy polarizable $\pi$-system of electrons. We have recently reported on the pyroelectricity of $1-\mathrm{NH}_{2}-3-\mathrm{NO}_{2}-\mathrm{C}_{6} \mathrm{H}_{4}, 1-\mathrm{OH}-3-\mathrm{NH}_{2}$ $\mathrm{C}_{6} \mathrm{H}_{4}$, and 1-OH-2,3- $\mathrm{Cl}_{2}-\mathrm{C}_{6} \mathrm{H}_{3}$ [1].

Large single crystals are needed for measurements of the pyroelectric coefficient of a solid. We have been able to grow large single crystals of m-chloronitrobenzene (CNB), 1-Cl-3- $\mathrm{NO}_{2}-\mathrm{C}_{6} \mathrm{H}_{4}$, p-nitrobenzonitrile (NBN), $1-\mathrm{CN}-4-\mathrm{NO}_{2}-\mathrm{C}_{6} \mathrm{H}_{4}$, and p-bromobenzonitrile $(\mathrm{BBN}), 1-\mathrm{CN}-4-\mathrm{Br}-\mathrm{C}_{6} \mathrm{H}_{4}$. The relatively simple molecular structure of these three compounds allows a comparison between pyroelectricity and molecular properties. CNB, NBN,

\footnotetext{
* Part of Dr.-Ing. Dissertation S. Fleck, Darmstadt.

Reprint requests to Prof. Dr. Al. Weiss, Institut für Physikalische Chemie, Physikalische Chemie III, Technische Hochschule Darmstadt, Petersenstr. 20, D-6100 Darmstadt, West Germany.
}

and BBN crystallize in the space groups $\mathrm{C}_{2 \mathrm{v}}^{9}-\mathrm{Pna} 2_{1}$, $\mathrm{C}_{2}^{2}-\mathrm{P} 2_{1}$, and $\mathrm{C}_{5}^{3}-\mathrm{Cm}$, respectively [2-4]. Therefrom it is seen that BBN has a pyroelectric coefficient which can point in any direction within the $a c$-plane of the crystal, $\boldsymbol{p}=\left(p_{1} 0 p_{3}\right)$. Such a behaviour has been studied for example on the ferroelectric lithium trihydrogen selenite [5] and on ammonium hydrogen-DL-malate monohydrate [6]. The other two compounds, CNB and NBN, show a polarization along the axis [001], $\boldsymbol{p}=\left(\begin{array}{lll}0 & 0 & p_{3}\end{array}\right)$, and along the axis $[010], \boldsymbol{p}=\left(0 p_{2} 0\right)$, respectively. For 1-Cl$3-\mathrm{NO}_{2}-\mathrm{C}_{6} \mathrm{H}_{4}$ the single crystal ${ }^{35} \mathrm{Cl}-\mathrm{NQR}$ spectrum was studied, together with the crystal structure, in detail [2].

\section{Experimental}

\section{Preparation}

The compounds $\mathrm{CNB}, \mathrm{NBN}$, and BBN used for the growth of single crystals were of commercial source (purity $>98 \%$ ). CNB was further purified by crystallization from ethanolic solution. Single crystals were obtained by cooling a saturated ethanolic solution from $T \cong 308 \mathrm{~K}$ down to room temperature; melting point $\left(T_{\mathrm{m}}\right)$ of $\mathrm{CNB}=318 \mathrm{~K}$. Large single crystals of this compound have been grown recently for ${ }^{35} \mathrm{Cl}$ single crystal NQR-spectroscopy [2]. The crystal axis could be identified by comparing the measurements on the optical goniometer with the crystal structure data. Crystal plates 
parallel to the (001) plane with an area $13 \leqq A / \mathrm{mm}^{2}$ $\leqq 25$ and thickness $0.7 \leqq d / \mathrm{mm} \leqq 1.0$ were cut with a wire saw.

NBN was purified by sublimation under reduced pressure, and by chance a large single crystal was obtained during this procedure $\left(T_{\mathrm{m}}=421 \mathrm{~K}\right)$. The crystals of NBN show a perfect cleavage plane, which contains the polar axis [010]. Within the cleavage plane the direction of the polar axis was identified by pyroelectric measurements. Than crystal plates perpendicular to [010] with an area $9 \leqq A / \mathrm{mm}^{2} \leqq 15$ and thickness $0.9 \leqq d / \mathrm{mm} \leqq 1.1$ were cut. We have not been able to produce larger plates because of the ease of cleavage. From ethanolic solution small plates grow which are elongated along the polar axis.

The third substance discussed here, BBN, was purified by zone melting and single crystals could be obtained by this method $\left(T_{\mathrm{m}}=386 \mathrm{~K}\right)$. The orientation of the axes of the single crystal was determined by X-ray diffraction. Crystal plates with the zone axis [010] and varying orientation of their normal with respect to [100] and with dimensions $16 \leqq A / \mathrm{mm}^{2} \leqq 60$ and $0.7 \leqq d / \mathrm{mm} \leqq 1.1$ were cut.

For the measurement of the dielectric constants and the pyroelectric coefficients of $\mathrm{CNB}, \mathrm{NBN}$, and BBN, crystal plates prepared in the way described above, were polished and painted at the two opposite large faces with an air drying silver paste. In this way single crystal capacitors for the experiments were obtained [7].

\section{Measurements of the Dielectric Constants and the Pyroelectric Coefficients}

The complex dielectric constant, $\varepsilon=\varepsilon^{\prime}-i \varepsilon^{\prime \prime}$, was found from impedance measurements of oriented single crystal capacitors, applying a bridge method described in [7]. The temperature range covered was $200 \leqq T / \mathrm{K} \leqq T_{\mathrm{d}}\left(T_{\mathrm{d}}=\right.$ decomposition temperature $)$. Quite below the melting point, due to sublimation disturbances in the measurements occurred. This influences the accuracy of the dielectric measurements in the case of CNB, $\Delta \varepsilon= \pm 5 \%$. In the case of NBN only elongated crystal plates were available, and again $\Delta \varepsilon= \pm 5 \%$. The dielectric constant of $\mathrm{BBN}$ is accurate to $\pm 3 \%$.

The temperature dependence of the pyroelectric coefficient at constant stress was measured in two different ways as described in [1,7]. Either the single crystal capacitor is heated or cooled with a constant rate, $0.5 \leqq \Delta T \cdot \Delta t^{-1} /\left(\mathrm{K} \cdot \mathrm{min}^{-1}\right) \leqq 4$. The resulting pyroelectric current is than measured by means of a shunt resistance $\left(10^{10} \Omega\right)$ and an ultra high impedance electrometer. In the second way the temperature of the sample is varied sinusoidal and the pyroelectric coefficient is calculated from the responding sinusoidal pyroelectric current. The second method was not employed in case of NBN because the pyroelectric coefficient was too small to be determined thereby reliably.

The pyroelectric coefficients of the three substances under investigation were studied on several individual crystal plates for each compound. The temperature range $100 \leqq T / \mathrm{K} \leqq T_{\mathrm{d}}$ was covered and an accuracy of $\pm 10 \%$ in $\boldsymbol{p}$ was obtained.

\section{Results}

\section{Dielectric Constants}

The complex dielectric constants, $\varepsilon=\varepsilon^{\prime}-i \varepsilon^{\prime \prime}$, of $\mathrm{CNB}$ and NBN were measured in the direction of the polar axes only. The component of the dielectric tensor, $\varepsilon_{33}^{\prime}$, of CNB shows a steady increase in the range $200 \leqq T / \mathrm{K} \leqq 310$ from 3.6 to 4 , and $\mathrm{d} \varepsilon^{\prime} / \mathrm{d} T$ increases with $T$, see Figure 1. The steep increase of $\varepsilon_{33}^{\prime}$ above $306 \mathrm{~K}$ is due to an onset of decomposition.

The component of the dielectric tensor in the direction of the polar axis of NBN, $\varepsilon_{22}^{\prime}$, is comparable to that of $\mathrm{CNB}$, but the temperature dependence is quite different (Figure 2). While $\varepsilon_{22}^{\prime}$ rises from 3.4 to 3.9 in the range $200 \leqq T / \mathrm{K} \leqq 340$, $\mathrm{d} \varepsilon_{22}^{\prime} / \mathrm{d} T$ decreases with $T$. A maximum of $\varepsilon_{22}^{\prime}$ at about $340 \mathrm{~K}$ appears. Thereafter $\mathrm{d} \varepsilon^{\prime} / \mathrm{d} T$ is negative and the slope grows with $T$. At about $380 \mathrm{~K}$ cracks appear in the single crystals of NBN making measurements of the dielectric constant for $T>395 \mathrm{~K}$ useless.

In the case of BBN the whole dielectric tensor $\left(\varepsilon_{i j}\right)$ was studied, $i, j=1,2,3 ; \varepsilon_{i j}=\varepsilon_{j i} ; \varepsilon_{12}, \varepsilon_{23}=0$. $\varepsilon_{22}$ can be measured directly on (010)-crystal plates (curve $\mathrm{V}$ in Figure 3). The other three tensor components, $\varepsilon_{11}, \varepsilon_{13}$, and $\varepsilon_{33}$, describe an ellipse in the $a c$-plane of the crystal. They have been calculated from measurements of the dielectric constant in different directions in the ac-plane (curves I-IV in Fig. 3) as described in $[6,8]$. The resulting dielectric tensor does not change, neither in orientation nor in magnitude of the components, in the investigated 


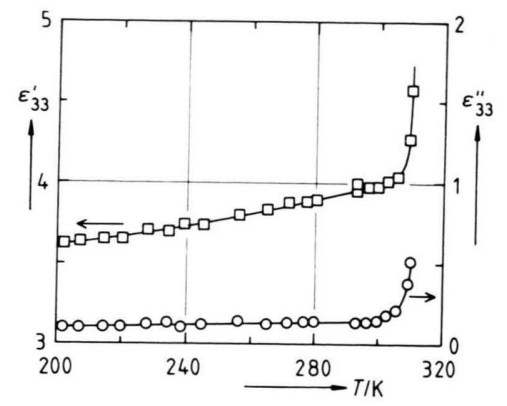

Fig. 1. Dielectric constant $\varepsilon_{33}^{\prime}(\square), \varepsilon_{33}^{\prime \prime}(\circ)$ in the direction of the polar axis $2_{1}$ of $1-\mathrm{Cl}-3-\mathrm{NO}_{2}-\mathrm{C}_{6} \mathrm{H}_{4}$ vs. temperature.

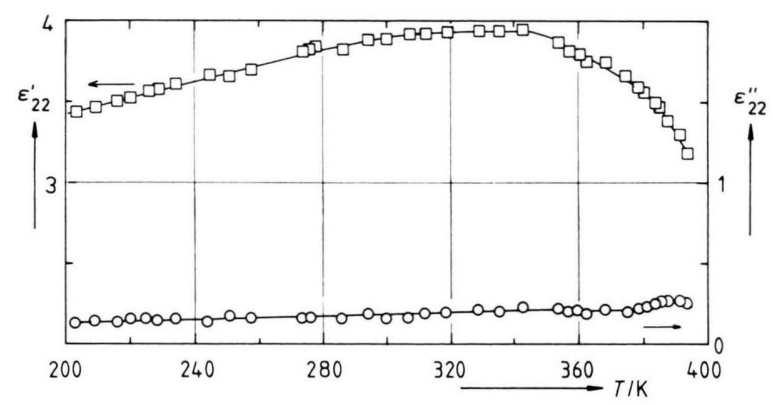

Fig. 2. Dielectric constant $\varepsilon_{22}^{\prime}(\square), \varepsilon_{22}^{\prime \prime}(\circ)$ in the direction of the polar axis $2_{1}$ of $1-\mathrm{CN}-4-\mathrm{NO}_{2}-\mathrm{C}_{6} \mathrm{H}_{4}$ vs. temperature.

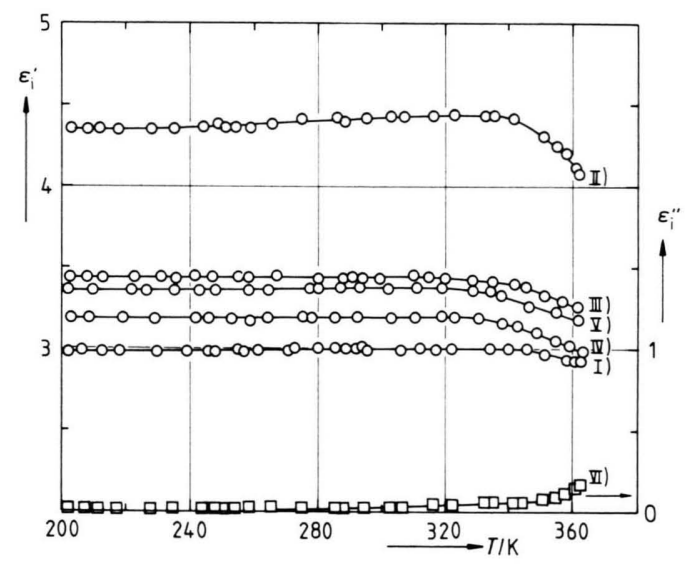

Fig. 3. Components of the dielectric constant in the acplane of $1-\mathrm{CN}-4-\mathrm{Br}-\mathrm{C}_{6} \mathrm{H}_{4}, \quad \varepsilon_{i}^{\prime}(0)$, characterized by $\theta=$ angle between the axis [100] and the direction of measurement vs. temperature. I)-IV): I) $\theta_{\mathrm{I}}=109^{\circ}$; II) $\theta_{\mathrm{II}}=19^{\circ}$; III) $\theta_{\mathrm{III}}=74^{\circ}$; IV) $\theta_{\mathrm{IV}}=141^{\circ}$; V) corresponds to the measurement on a plate cut parallel to the plane $(010)$, $\varepsilon_{22}^{\prime}$. VI) $\varepsilon^{\prime \prime}(\square)$ corresponding to all directions.

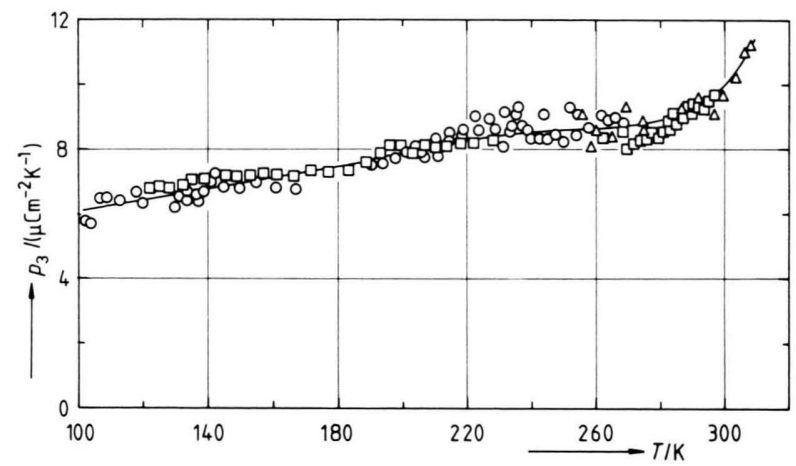

Fig. 4. Pyroelectric coefficient of 1-Cl-3- $\mathrm{NO}_{3}-\mathrm{C}_{6} \mathrm{H}_{4}, p_{3}$, vs. temperature. Squares represent measurements done with increasing temperature, circles with decreasing temperature, and triangles with sinusoidal temperature oscillation.

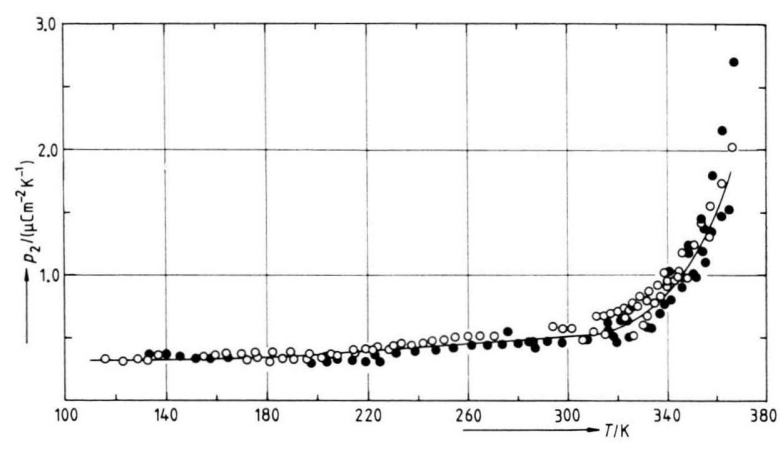

Fig. 5. Pyroelectric coefficient of $1-\mathrm{CN}-4-\mathrm{NO}_{2}-\mathrm{C}_{6} \mathrm{H}_{4}, p_{2}$, vs. temperature. Full circles represent measurements done with increasing temperature, open ones with decreasing temperature.

temperature range up to $340 \mathrm{~K}: \varepsilon_{11}=3.14 ; \varepsilon_{13}=0.52$; $\varepsilon_{33}=4.17 ; \varepsilon_{22}=3.38$. The dielectric tensor in the principal coordinate system found by the circle construction of Mohr [8] reads: $\varepsilon_{11}=2.93 ; \varepsilon_{22}=3.38$; $\varepsilon_{33}=4.39$. The angle $\Phi$ between the principal axis of the dielectric ellipse in the $a c$-plane and the crystallographic axis [100] is $22.6^{\circ}$. For temperatures $>340 \mathrm{~K}$ the dielectric constant decreases.

\section{Pyroelectric Coefficient}

The pyroelectric coefficients at constant stress of the three substances under investigation have been determined in the temperature range $100 \leqq T / \mathrm{K}$ $\leqq T_{\mathrm{d}}$. The temperature dependences of $p_{3}(\mathrm{CNB})$ and $p_{2}(\mathrm{NBN})$ are shown in Figs. 4 and 5 , respectively. Both curves exhibit an increasing $|\boldsymbol{p}|$ with increasing temperature, despite the fact that $p_{3}(\mathrm{CNB}) \cong 20 \cdot p_{2}(\mathrm{NBN})$ for $100 \leqq T / \mathrm{K} \leqq 300$. For 


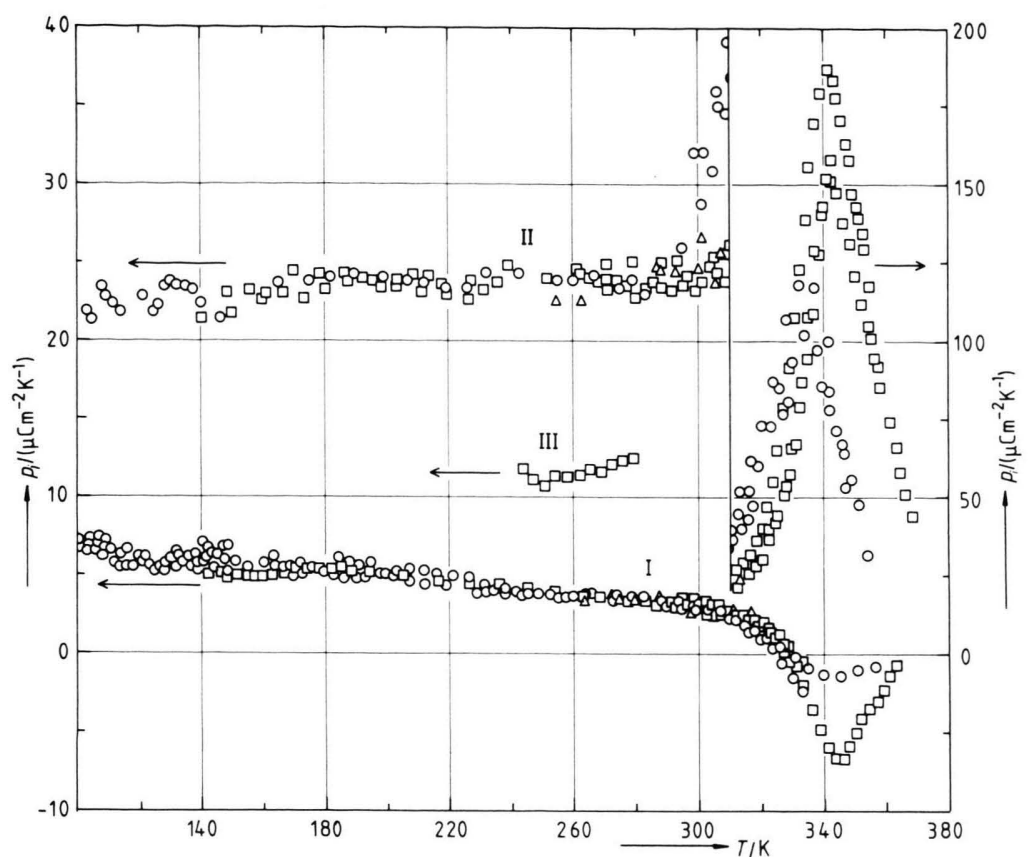

Fig. 6. Components of the pyroelectric vector, $p_{i}$, in different directions within the $a c$-plane of $1-\mathrm{CN}$ $4-\mathrm{Br}-\mathrm{C}_{6} \mathrm{H}_{4}$ characterized by $\theta_{i}$, vs. temperature. $\theta_{i}$ is defined as in legend to Fig. 3: I) $\theta_{\mathrm{I}}=109^{\circ}$; II) $\theta_{\mathrm{II}}=19^{\circ}$; III) $\theta_{\mathrm{III}}=74^{\circ}$. The squares represent measurements done with increasing temperature, circles correspond to decreasing temperature. The data points obtained by use of sinusoidal temperature oscillation method are labeled by triangles. temperatures $>300 \mathrm{~K}$ the curvature of $p_{3}(\mathrm{CNB})$ steepens due to onset of decomposition.

For $p_{2}(\mathrm{NBN})$ a pronounced increase of $p_{2}$ with raising $T$ is found, too. The increase starts at $T=320 \mathrm{~K}$ and apparent values of $p_{2} \cong 50 \mu \mathrm{C} \mathrm{m}^{-2} \mathrm{~K}^{-1}$ at $T \cong 380 \mathrm{~K}$ (not shown in Fig. 5) have been registered. After heating to $T<380 \mathrm{~K}$ the curve displayed in Fig. 5 can be reproduced on cooling. This is not possible if the sample is heated above $380 \mathrm{~K}$. Disturbances due to cracks in the crystals appear and measurements of the pyroelectric coefficient have been found to be of no further use. NBN was studied by differential thermal analysis (DTA), too, and both on heating and cooling a phase transition at $T_{\mathrm{c}}=386 \mathrm{~K}$ was found. Obviously the phase transition is reversible but accompanied by volume changes which give rise to cracks in the crystals. The decrease of $\varepsilon_{22}^{\prime}$ and the discontinuity of $p_{2}(\mathrm{NBN})=f(T)$ at about $T=380 \mathrm{~K}$ are in accordance with $T_{\mathrm{c}}$ found from DTA.

$\boldsymbol{p}$ of BBN was found from independent measurements of the pyroelectric coefficient in two directions orthogonal to each other within the $a c$-plane (Fig. 6), the directions being characterized by $\theta$, the angle between the direction of measurement and the axis [100]. For an unambiguous assignment of the direction of $\boldsymbol{p}$ a measurement in a third direction was done for $240 \leqq T / \mathrm{K} \leqq 280$, the sign being still undetermined. Both, the absolute value and the direction of $\boldsymbol{p}$, characterized by $\psi$, the angle between $\boldsymbol{p}$ and the axis [100], are shown in Figure 7.

$\boldsymbol{p}$ of $\mathrm{BBN}$ is almost constant for $100 \leqq T / \mathrm{K}$ $\leqq 320$, exhibiting the largest pyroelectric coefficient of the three substances investigated. Above $320 \mathrm{~K}$ a maximum of the pyroelectric coefficient is found, reaching $|\boldsymbol{p}|_{\max } \cong 7 \cdot|\boldsymbol{p}|_{100 \leqq T / K \cong 300}$. The temperature of $\boldsymbol{p}_{\max }, T_{\max }$, was determined by the method of constant temperature change. In heating cycles $T_{\max } \cong 343 \mathrm{~K}$ and in cooling cycles $T_{\max } \cong$ $333 \mathrm{~K}$. Whether $\boldsymbol{p}$ goes to zero for $T>T_{\max }$ and the origin of the maximum in $\mid \boldsymbol{p}$ is a phase transition could not be proved. DTA does not show any enthalpy effect and $T_{\mathrm{m}}=386 \mathrm{~K}$ is reached within the observed decay range of $\boldsymbol{p}(\mathrm{BBN})$. Currents of non pyroelectric origin appear if the crystal is kept at $T=375 \mathrm{~K}$ for about $10 \mathrm{~min}$. Thereafter the curve $\boldsymbol{p}=f(T)$ is not reproducible. Sublimation is one possible source of this behaviour.

Furthermore for BBN, symmetry $\mathrm{m}$, a strong angular dependence $\boldsymbol{p}=f(\psi)$ is observed with a nearly constant $\mathrm{d} \psi / \mathrm{d} T$ in the range $100 \leqq T / \mathrm{K}$ $\leqq 300$ from $\psi=2.5^{\circ}$ to $\psi=11.5^{\circ}$. Thereafter the curvature of $\psi=f(T)$ steepens and an angle of $\psi=21^{\circ}$ is reached at maximum. From all observa- 


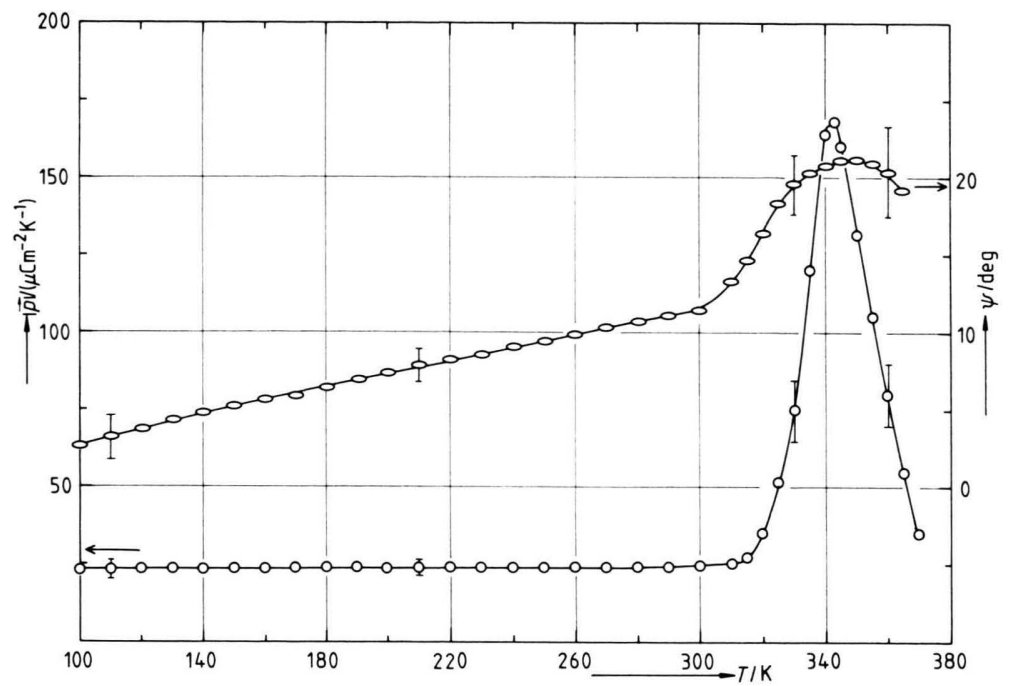

Fig. 7. Absolute value $|\boldsymbol{p}|$ (O) and direction $\psi(0)$ of the pyroelectric coefficient of $1-\mathrm{CN}-4-\mathrm{Br}-\mathrm{C}_{6} \mathrm{H}_{4}$ vs. temperature.

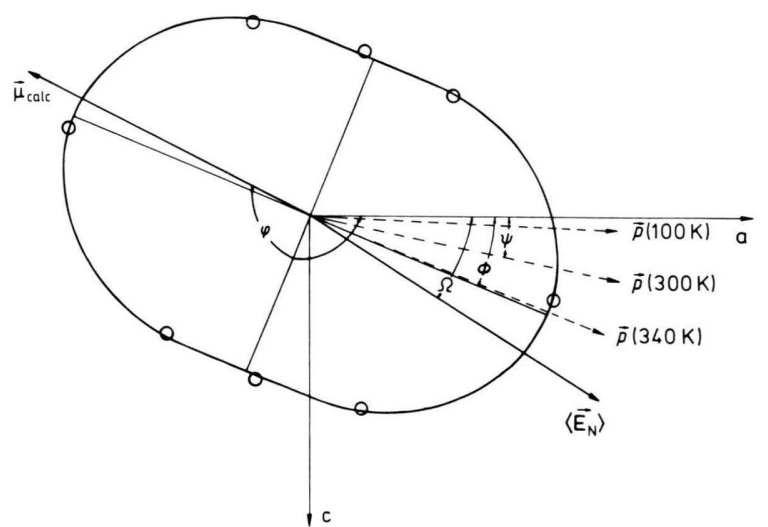

Fig. 8. Dielectric ellipse, $\varepsilon(\theta)(0)$, and pyroelectric vector, $\boldsymbol{p}$ (the sign of $\boldsymbol{p}$ is unknown) of $1-\mathrm{CN}-4-\mathrm{Br}-\mathrm{C}_{6} \mathrm{H}_{4}$, together with $\boldsymbol{\mu}_{\text {calc }}$ and $\left\langle\boldsymbol{E}_{\mathrm{N}}\right\rangle$.

Table 1. Dielectric constants and pyroelectric coefficients of 1-Cl-3- $-\mathrm{NO}_{2}-\mathrm{C}_{6} \mathrm{H}_{4}$ (CNB), 1-CN-4- $\mathrm{NO}_{2}-\mathrm{C}_{6} \mathrm{H}_{4}$ (NBN), and $1-\mathrm{CN}-4-\mathrm{Br}-\mathrm{C}_{6} \mathrm{H}_{4}(\mathrm{BBN})$ for selected temperatures.

\begin{tabular}{lllll}
\hline$T / \mathrm{K}$ & $\mathrm{CNB}$ & $\mathrm{NBN}$ & $\mathrm{BBN}$ & \\
\hline$\varepsilon_{i}$ & & & & \\
$200 \mathrm{~K}$ & $\varepsilon_{33}=3.61$ & $\varepsilon_{22}=3.43$ & $\varepsilon_{11}=3.14$, & $\varepsilon_{13}=0.52$, \\
& & & $\varepsilon_{33}=4.17$, & $\varepsilon_{22}=3.38$ \\
$300 \mathrm{~K}$ & $\varepsilon_{33}=4.00$ & $\varepsilon_{22}=3.90$ & $\varepsilon_{11}=3.14$, & $\varepsilon_{13}=0.52$, \\
& & & $\varepsilon_{33}=4.17$, & $\varepsilon_{22}=3.38$ \\
$p_{i} \mid / \mu \mathrm{C} \mathrm{m}^{-2} \mathrm{~K}^{-1}$ & & & \\
100 & $p_{3}=6.2$ & $p_{2}=0.32$ & $p_{1}=23.6$, & $p_{3}=1.1$ \\
180 & $p_{3}=7.5$ & $p_{2}=0.35$ & $p_{1}=23.8$, & $p_{3}=2.8$ \\
260 & $p_{3}=8.7$ & $p_{2}=0.45$ & $p_{1}=23.7$, & $p_{3}=4.1$ \\
340 & & $p_{2}=0.86$ & $p_{1}=164.0$, & $p_{3}=5.2$ \\
\hline
\end{tabular}

tions combined, we conclude that a reversible phase transition of the order-disorder type occurs at $T_{\mathrm{c}}=T_{\max } \cong 340 \mathrm{~K}$, which is accompanied by a very small enthalpy of transition. The assumption of an order-disorder transition of $\mathrm{BBN}$ is supported by the fact that it is chemically and structurally related to $1-\mathrm{Cl}-4-\mathrm{Br}-\mathrm{C}_{6} \mathrm{H}_{4}$, which is known to be disordered in the solid state $[9-11]$.

In Table 1 the obtained values for the dielectric constants and pyroelectric coefficients of the three substances under investigation are given for selected temperatures. In Fig. 8 the dielectric ellipse in the $a c$-plane is shown for BBN. Additionally the direction of the pyroelectric coefficient is plotted for $T=100 \mathrm{~K}, 300 \mathrm{~K}$, and $340 \mathrm{~K}$. By comparison of the dielectric ellipse with a schematic display of the structure of BBN in Fig. 9, it is seen that the principle axis of the ellipse is nearly parallel to the direction [101]. The direction of the pyroelectric coefficient drifts with increasing temperature towards [101], too.

\section{Dipole Moments}

Experimental dipole moments of CNB, NBN, and $\mathrm{BBN}$ have been reported by McClellan [12] as determined in the gaseous state and/or in solutions. We have calculated the charge distributions of the 
Table 2. Calculated charge distributions, in units of the elementary charge, for $1-\mathrm{Cl}-3-\mathrm{NO}_{2}-\mathrm{C}_{6} \mathrm{H}_{4}(\mathrm{CNB}), 1-\mathrm{CN}$ $4-\mathrm{NO}_{2}-\mathrm{C}_{6} \mathrm{H}_{4}(\mathrm{NBN})$, and $1-\mathrm{CN}-4-\mathrm{Br}_{-} \mathrm{C}_{6} \mathrm{H}_{4}(\mathrm{BBN})$.

\begin{tabular}{lrlrlr}
\hline CNB & & NBN & \multicolumn{3}{l}{ BBN } \\
\hline $\mathrm{C}(1)$ & 0.32 & $\mathrm{C}(1)$ & 0.12 & $\mathrm{C}(1)$ & -0.08 \\
$\mathrm{C}(2)$ & -0.28 & $\mathrm{C}(2)$ & -0.15 & $\mathrm{C}(2)$ & -0.08 \\
$\mathrm{C}(3)$ & 0.01 & $\mathrm{C}(3)$ & -0.06 & $\mathrm{C}(3)$ & -0.24 \\
$\mathrm{C}(4)$ & -0.20 & $\mathrm{C}(4)$ & -0.12 & $\mathrm{C}(4)$ & 0.16 \\
$\mathrm{C}(5)$ & -0.05 & $\mathrm{C}(5)$ & -0.07 & $\mathrm{C}(5)$ & -0.24 \\
$\mathrm{C}(6)$ & -0.30 & $\mathrm{C}(6)$ & -0.15 & $\mathrm{C}(6)$ & -0.08 \\
$\mathrm{H}(\mathrm{C} 2)$ & 0.20 & $\mathrm{H}(\mathrm{C} 2)$ & 0.16 & $\mathrm{H}(\mathrm{C} 2)$ & 0.15 \\
$\mathrm{H}(\mathrm{C} 4)$ & 0.19 & $\mathrm{H}(\mathrm{C} 3)$ & 0.17 & $\mathrm{H}(\mathrm{C} 3)$ & 0.16 \\
$\mathrm{H}(\mathrm{C} 5)$ & 0.15 & $\mathrm{H}(\mathrm{C} 5)$ & 0.16 & $\mathrm{H}(\mathrm{C} 5)$ & 0.16 \\
$\mathrm{H}(\mathrm{C} 6)$ & 0.15 & $\mathrm{H}(\mathrm{C} 6)$ & 0.16 & $\mathrm{H}(\mathrm{C} 6)$ & 0.15 \\
$\mathrm{Cl}$ & -0.07 & $\mathrm{C}(7)$ & 0.03 & $\mathrm{C}(7)$ & -0.16 \\
& & $\mathrm{~N}(\mathrm{C} 7)$ & -0.14 & $\mathrm{~N}(\mathrm{C} 7)$ & 0.08 \\
$\mathrm{~N}(\mathrm{C} 3)$ & 1.14 & $\mathrm{~N}(\mathrm{C} 4)$ & 1.15 & $\mathrm{Br}$ & 0.02 \\
$\mathrm{O}(1, \mathrm{~N})$ & -0.62 & $\mathrm{O}(1, \mathrm{~N})$ & -0.65 & & \\
$\mathrm{O}(2, \mathrm{~N})$ & -0.64 & $\mathrm{O}(2, \mathrm{~N})$ & -0.61 & & \\
\hline
\end{tabular}

Table 3. Experimental and calculated dipole moments and the electric field at the site of a reference molecule $\mathrm{R}$ created by the neighbouring molecules for 1-Cl-3- $\mathrm{NO}_{2}-\mathrm{C}_{6} \mathrm{H}_{4}$ (CNB), 1-CN-4- $\mathrm{NO}_{2}-\mathrm{C}_{6} \mathrm{H}_{4}(\mathrm{NBN})$, and 1-CN-4-Br- $\mathrm{C}_{6} \mathrm{H}_{4}$ $(\mathrm{BBN})$.

\begin{tabular}{llll}
\hline & CNB & NBN & BBN \\
\hline$\left|\boldsymbol{\mu}_{\text {lit }}\right| \cdot 10^{30} / \mathrm{C} \mathrm{m} \mathrm{[12]}$ & $10.7-14.3$ & $0.0-2.4$ & 8.9 \\
$\boldsymbol{\mu}_{\text {calc }} \mid \cdot 10^{30} / \mathrm{C} \mathrm{m}^{*}$ & 16.9 & 9.1 & 6.7 \\
$\left.\mu_{\text {calc, } \mathrm{P}} \mid \cdot 10^{30} / \mathrm{C} \mathrm{m}^{-1}\right)$ & 11.9 & 7.1 & 6.0 \\
$\left\langle E_{\mathrm{N}, \mathrm{P}}\right\rangle \cdot 10^{-9} /\left(\mathrm{V} \mathrm{m}^{-1}\right)^{* *}$ & 2.830 & 1.079 & 0.5204 \\
\hline
\end{tabular}

* The angle between $\boldsymbol{\mu}_{\text {calc }}$ and [100] for BBN is $\varphi=207^{\circ}$.

** The angle between $\left\langle\boldsymbol{E}_{\mathrm{N}}\right\rangle$ and [100] for BBN is $\Omega=32^{\circ}$.

three substances under investigation and therefrom the dipole moments for the solid state by the quantum chemical INDO-SCEF method introduced in [6]. Semiempirical molecular orbital (MO)-calculations have been employed in an intermediate neglect of differential overlap (INDO)-type-approximation; intermolecular interactions have been simulated in a self-consistent electric field (SCEF) approach. The electric field was created in the cases of CNB and NBN by 10 and in the case of BBN by 14 neighbouring molecules. The resulting charge distributions are given in Table 2. The atomic numbering schemes used are displayed in Fig. $10 \mathrm{a}-\mathrm{c}$.

In Table 3 the dipole moments obtained from the calculated charge distributions, $\boldsymbol{\mu}_{\text {calc }}$, are given together with the component of the dipole moment in the direction of the polarisation, $\mu_{\text {calc. P. Additionally }}$

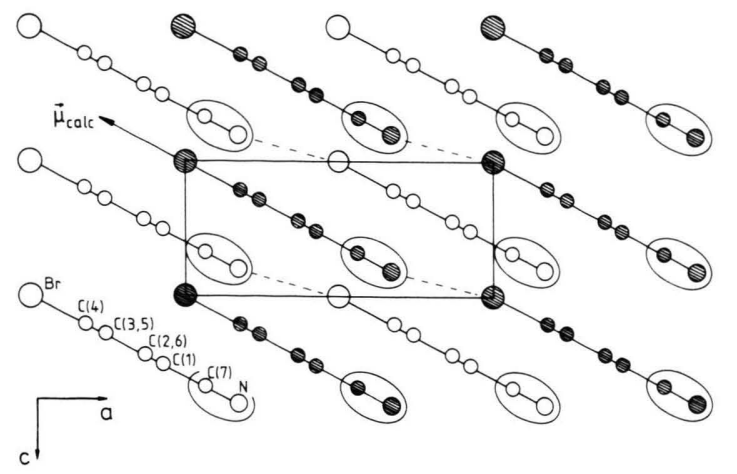

Fig. 9. Schematic display of the molecular arrangement of $1-\mathrm{CN}-4-\mathrm{Br}-\mathrm{C}_{6} \mathrm{H}_{4}$ along the axis [010]. The hatched molecules are in the plane $(a 0 c)$, the other ones in the plane $\left(a \frac{1}{2} c\right)$.

for BBN, symmetry $\mathrm{m}$, the angle between $\boldsymbol{\mu}$ and the axis [100] $(\varphi)$ is given in this table. For comparison we have also listed the dipole moments reported by McClellan $\boldsymbol{\mu}_{\text {lit }}$. In the cases of CNB and BBN, $\boldsymbol{\mu}_{\text {calc }}$ is in satisfactory agreement with $\boldsymbol{\mu}_{\text {lit }}$, if the accuracy of the experimental and calculated values is considered $[6,12]$. In the case of NBN a summation of uncertainties in the quantum chemical calculations obviously leads to a much to high a value of $\boldsymbol{\mu}_{\text {calc }}$. This probably occurs because the dipole moment of NBN results mainly from the difference in the partial dipole moments due to groups with comparable electron withdrawing effects in opposite direction.

From the charge distribution and the crystal structure data [2-4], we have calculated the electric field $\boldsymbol{E}_{\mathrm{N}}(x, y, z)$ created by the neighbouring molecules $\mathrm{N}$ at the site of a reference molecule $\mathrm{R}[6,7]$,

$\boldsymbol{E}_{\mathrm{N}}(x, y, z)=\frac{1}{4 \pi \varepsilon_{0}} \sum_{N} \sum_{j} \frac{q_{j} \cdot \boldsymbol{r}_{j}}{\left.\boldsymbol{r}_{j}\right|^{3}} \equiv \frac{1}{4 \pi \varepsilon_{0}} \boldsymbol{S}_{\mathrm{N}}(x, y, z)$

with $\boldsymbol{r}_{j}=$ radius vector from atom $j$ in the external molecule $\mathrm{N}$ to the reference unit $\mathrm{R}, q_{j}=$ charge of atom $j$, and $\boldsymbol{S}_{\mathrm{N}}=$ abbreviation for the summation. $\boldsymbol{E}_{\mathrm{N}}(x, y, z)$ was averaged over the volume of the reference molecule $V_{\mathrm{R}}$, leading to

$\left\langle\boldsymbol{E}_{\mathrm{N}}\right\rangle=\frac{1}{V_{\mathrm{R}}} \sum \boldsymbol{E}_{\mathrm{N}}(x, y, z) \Delta V \equiv \frac{1}{4 \pi \varepsilon_{0}}\left\langle\boldsymbol{S}_{\mathrm{N}}\right\rangle$.

In the cases of CNB, NBN, and BBN 70, 94, and 126 neighbouring molecules, respectively, are used to create the electric field. The resulting values for $\left\langle\boldsymbol{E}_{\mathrm{N}}\right\rangle$ and $\left\langle E_{\mathrm{N}, \mathrm{P}}\right\rangle=$ component of $\left\langle\boldsymbol{E}_{\mathrm{N}}\right\rangle$ in the direc- 
tion of polarisation, are given in Table 3. For BBN the angle, $\Omega$, between $\left\langle\boldsymbol{E}_{\mathrm{N}}\right\rangle$ and the axis [100] is listed, too. It can be seen from Figs. 8 and 9 that the direction of the dipole moment of BBN coincides with the molecular axis.

\section{Discussion}

The three substances, m-chloronitrobenzene, $\mathrm{CNB}$, p-nitrobenzonitrile, NBN, and p-bromobenzonitrile, BBN, show comparable dielectric properties with $3<\varepsilon^{\prime}<4.5$ in the whole temperature range studied. However the temperature dependences $\mathrm{d} \varepsilon^{\prime} / \mathrm{d} T$ are different. On the other hand strong differences appear in the pyroelectric properties with $0.3<\boldsymbol{p} \mid /\left(\mu \mathrm{C} \mathrm{m}^{-2} \mathrm{~K}^{-1}\right)<170$. These variations do not parallel the diverse dipole moments of the three substances. In the case of NBN it is true that an almost negligible dipole moment is accompanied by a very small $|\boldsymbol{p}|$. In case of CNB and BBN, however, $|\boldsymbol{\mu}|(\mathrm{CNB})>|\boldsymbol{\mu}|(\mathrm{BBN})$, while $\boldsymbol{p}(\mathrm{CNB})<\boldsymbol{p}(\mathrm{BBN})$ (see Table 3$)$.

In a detailed discussion $[6,7]$ it was shown that the temperature dependence of the polarization $\boldsymbol{P}$, e.g. the value of the pyroelectric coefficient $\boldsymbol{p}$, can be calculated as a function of molecular and crystal properties, $\boldsymbol{p}=f\left(\varepsilon_{\mathrm{P}}, \boldsymbol{\alpha}, \boldsymbol{\mu}, \boldsymbol{E}_{\mathrm{L}}, \boldsymbol{E}_{\mathrm{N}}\right)$ with $\alpha=$ dipole polarizability and $\boldsymbol{E}_{\mathrm{L}}=$ Lorentz field [8]. The resulting equation for the pyroelectric coefficient in the employed model is

$$
\begin{aligned}
\boldsymbol{p}= & \frac{\mathrm{d} \boldsymbol{P}}{\mathrm{d} T}=\frac{N_{\mathrm{A}}}{3 \bar{V}}\left(\varepsilon_{\mathrm{p}}+2\right) \cdot|\boldsymbol{\mu}| \cdot \frac{\mathrm{d} \cos \delta}{\mathrm{d} T} \\
& +\frac{1}{4 \pi}\left(\varepsilon_{\mathrm{p}}-1\right) \cdot\left|\left\langle\boldsymbol{S}_{\mathrm{N}}\right\rangle\right| \cdot \frac{\mathrm{d} \cos \beta}{\mathrm{d} T} \\
& +\left(\frac{N_{\mathrm{A}}}{3 \bar{V}} \cdot|\boldsymbol{\mu}| \cdot \cos \delta+\frac{1}{4 \pi} \cdot\left|\left\langle\boldsymbol{S}_{\mathrm{N}}\right\rangle\right| \cdot \cos \beta\right) \frac{\mathrm{d} \varepsilon_{\mathrm{p}}}{\mathrm{d} T} \\
= & \boldsymbol{p}_{\mathrm{I}}+\boldsymbol{p}_{\mathrm{II}}+\boldsymbol{p}_{\mathrm{III}}
\end{aligned}
$$

with $1 / \bar{V}=\varrho / M=$ number of molecules per unit volume, $\varrho=$ mass density, $M=$ molar mass, $N_{\mathrm{A}}=$ Avogadro number, $\varepsilon_{\mathrm{P}}=$ dielectric constant in the direction of $\boldsymbol{P}, \delta=\Varangle(\boldsymbol{\mu}, \boldsymbol{P})$, and $\beta=\Varangle\left(\left\langle\boldsymbol{E}_{\mathrm{N}}\right\rangle, \boldsymbol{P}\right)$. In (3) the temperature dependence of the crystal volume is already neglected, i.e. $\bar{V}=$ const in the temperature range considered.

In case of $\mathrm{CNB}$ and $\mathrm{NBN} \varepsilon_{\mathrm{P}}$ corresponds to $\varepsilon_{33}(\mathrm{CNB})$ and $\varepsilon_{22}(\mathrm{NBN})$, respectively. Values for $\varepsilon_{\mathrm{P}}$ can be found in Figs. 1 and $2 ; \mathrm{d} \varepsilon_{\mathrm{P}} / \mathrm{d} T$ can be<smiles>[O-][N+]([O-])([O-])OC1C(O)OC(Cl)C(O)C1O</smiles><smiles>CC1OC(=O)OC(C)(OC(=O)OC#N)OC1O</smiles><smiles>CC1OC(OC#N)C(O)C(Br)C1C</smiles>

Fig. 10. Atomic numbering scheme of a) $1-\mathrm{Cl}-3-\mathrm{NO}_{2}-\mathrm{C}_{6} \mathrm{H}_{4}$, b) $1-\mathrm{CN}-4-\mathrm{NO}_{2}-\mathrm{C}_{6} \mathrm{H}_{4}$, and c) $1-\mathrm{CN}-4-\mathrm{Br}-\mathrm{C}_{6} \mathrm{H}_{4}$.

extracted therefrom. The variation of $\cos \delta$ and $\cos \beta$ with temperature, originating in a change of molecular dipole librational motions, can be described by a classical harmonic oscillator model $[1,13]$ :

$$
\begin{aligned}
\frac{\mathrm{d} \cos \delta}{\mathrm{d} T}=-\frac{\cos \delta}{2 T} & \left(J_{0}\left(\Phi_{x^{\prime}}\right) J_{1}\left(\Phi_{y^{\prime}}\right) \Phi_{y^{\prime}}\right. \\
& \left.+J_{0}\left(\Phi_{y^{\prime}}\right) J_{1}\left(\Phi_{x^{\prime}}\right) \Phi_{x^{\prime}}\right) .
\end{aligned}
$$

$J_{0}\left(\Phi_{i}\right), J_{1}\left(\Phi_{i}\right), i=x^{\prime}, y^{\prime}=$ Bessel functions of first kind and zero order, and of first kind and first order, respectively, $\Phi_{x^{\prime}}, \Phi_{y^{\prime}}=$ amplitudes of the dipole oscillations about the principal molecular axes $x^{\prime}$ and $y^{\prime}$. The $z^{\prime}$-axis defines the direction of the dipole moment while $x^{\prime}$ and $y^{\prime}$ are lying in a plane perpendicular to the $z^{\prime}$-axis. By classical harmonic approximation the mean square amplitude of libration about each axis is

$$
\Phi_{i}=\left(\frac{k T}{2 \pi^{2} v_{i}^{2} I_{i}}\right)^{1 / 2} .
$$

$I_{i}=$ moment of inertia, $v_{i}=$ librational frequency of the dipole around the axis $i$. For $\Phi_{i}<0.4$ there is $J_{0} \cong 1$ and $J_{1} \cong \Phi_{i} / 2$ in good approximation, e.g. with an accuracy of $4 \%$. Combining (4) and (5) and taking this approximation into account, leads to

$\frac{\mathrm{d} \cos \delta}{\mathrm{d} T}=-\cos \delta \frac{k}{8 \pi^{2}}\left(\frac{1}{v_{x^{\prime}}^{2} I_{x^{\prime}}}+\frac{1}{v_{y^{\prime}}^{2} I_{y^{\prime}}}\right)$. 
Table 4. Calculated pyroelectric coefficients for 1-Cl$3-\mathrm{NO}_{2}-\mathrm{C}_{6} \mathrm{H}_{4}$ (CNB), $1-\mathrm{CN}-4-\mathrm{NO}_{2}-\mathrm{C}_{6} \mathrm{H}_{4} \quad(\mathrm{NBN})$, and $1-\mathrm{CN}-4-\mathrm{Br}^{-} \mathrm{C}_{6} \mathrm{H}_{4}(\mathrm{BBN})$ at selected temperatures.

\begin{tabular}{llll}
\hline$T / \mathrm{K}$ & \multicolumn{2}{|c}{$\boldsymbol{p}_{\text {calc }} /\left(\mu \mathrm{C} \mathrm{m}^{-2} \mathrm{~K}^{-1}\right)$} & \\
\cline { 2 - 4 } & $\mathrm{CNB}$ & $\mathrm{NBN}$ & $\mathrm{BBN}$ \\
\hline 100 & 3.5 & 18.8 & 14.4 \\
180 & 4.4 & 18.8 & 12.9 \\
260 & 6.6 & 16.8 & 13.0 \\
340 & & 13.3 & 6.5 \\
\hline
\end{tabular}

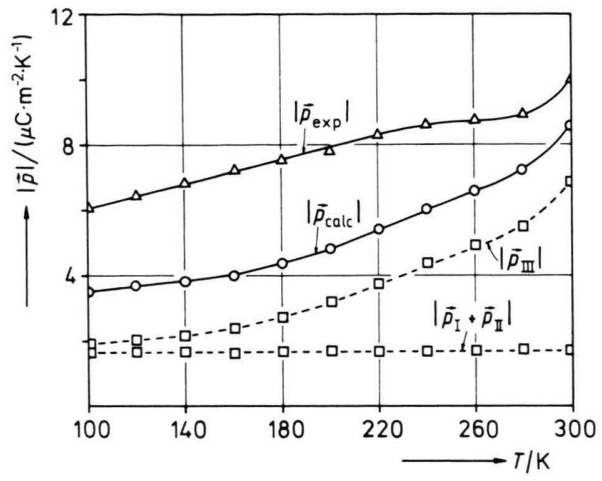

Fig. 11. Calculated pyroelectric coefficients $\left|\boldsymbol{p}_{\text {calc }}\right|$ (O), $\left|\boldsymbol{p}_{\mathrm{I}}+\boldsymbol{p}_{\mathrm{II}}\right|(\square)$, and $\boldsymbol{p}_{\mathrm{III}} \mid(\square)$, together with the measured one $\boldsymbol{p}_{\exp }(\triangle)$ for 1-Cl-3- $\mathrm{NO}_{2}-\mathrm{C}_{6} \mathrm{H}_{4}$ vs. temperature.

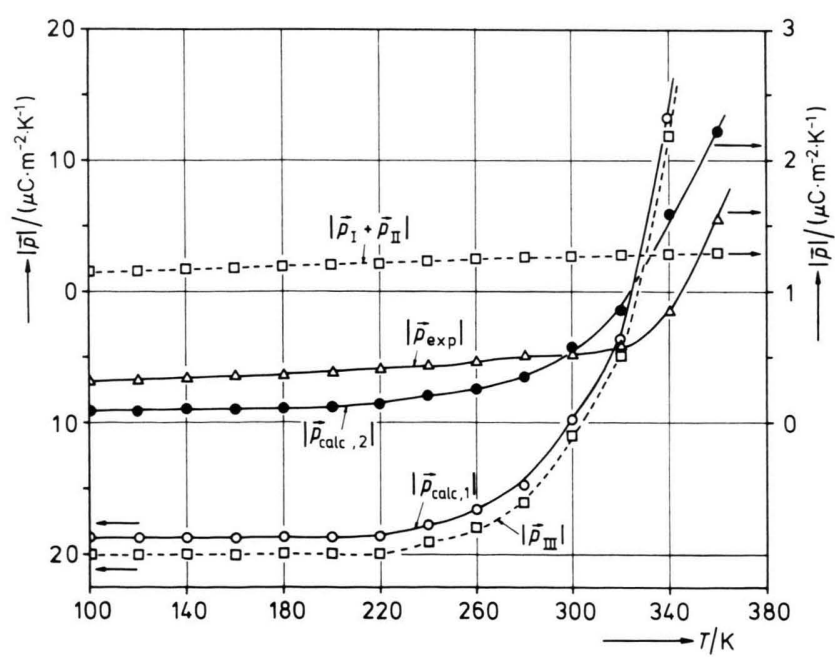

Fig. 12. Calculated pyroelectric coefficients $\left|\boldsymbol{p}_{\text {calc }}\right|(O, \bullet)$, $\left|\boldsymbol{p}_{\mathrm{I}}+\boldsymbol{p}_{\mathrm{II}}\right|(\square)$, and $\left|\boldsymbol{p}_{\mathrm{III}}\right|(\square)$, together with the measured one $\left|\boldsymbol{p}_{\exp }\right|(\triangle)$ for 1-CN-4- $\mathrm{NO}_{2}-\mathrm{C}_{6} \mathrm{H}_{4}$ vs. temperature.
This means that $\mathrm{d} \cos \delta / \mathrm{d} T$ is constant in the whole temperature range. Since $\beta=\delta+180^{\circ}, \mathrm{d} \cos \beta / \mathrm{d} T$ is equal to $-\mathrm{d} \cos \delta / \mathrm{d} T$.

Raman spectroscopic data are reported for $\mathrm{CNB}$ [14-16]. Therefrom the values of $\tilde{v}_{x^{\prime}}(\mathrm{CNB})=$ $25 \mathrm{~cm}^{-1}$ and $\tilde{v}_{y^{\prime}}(\mathrm{CNB})=59 \mathrm{~cm}^{-1}$ have been adopted for the frequencies of molecular librational motions of CNB. The principle moments of inertia $I_{x^{\prime}}(\mathrm{CNB})$ $=1.57 \cdot 10^{-44} \mathrm{~kg} \mathrm{~m}^{2}$ and $I_{y^{\prime}}(\mathrm{CNB})=1.20 \cdot 10^{-44}$ $\mathrm{kg} \mathrm{m}^{2}$ are given in [14], too. No spectroscopic data are available for NBN. In a first approximation the values of $\mathrm{d} \cos \delta / \mathrm{d} T$ for $\mathrm{CNB}$ have been adopted for NBN. This makes sense, since the molecular structure and the moments of inertia, respectively, of $\mathrm{CNB}$ and $\mathrm{NBN}$ are comparable; $I_{x^{\prime}}(\mathrm{NBN})=1.64$ $\cdot 10^{-44} \mathrm{~kg} \mathrm{~m}^{2}$ and $I_{y^{\prime}}(\mathrm{NBN})=1.43 \cdot 10^{-44} \mathrm{~kg} \mathrm{~m}^{2}$. With $\mathrm{d} \cos \delta / \mathrm{d} T$ and $\mathrm{d} \cos \beta / \mathrm{d} T$ found in this way and with $\mu_{\text {calc. } \mathrm{P}}$ and $\left\langle E_{\mathrm{N}, \mathrm{P}}\right\rangle$ resulting from the quantum chemical calculations, $\boldsymbol{p}(\mathrm{CNB})=f(T)$ and $\boldsymbol{p}(\mathrm{NBN})=f(T) \quad$ result. $\quad \boldsymbol{p}_{\text {calc }} \mid(\mathrm{CNB})=f(T)$ and $\boldsymbol{p}_{\text {calc }}(\mathrm{NBN})=f(T)$ are shown in Figs. 11 and 12, respectively. The components $\left(\boldsymbol{p}_{\mathrm{I}}+\boldsymbol{p}_{\mathrm{II}}\right)$ and $\left|\boldsymbol{p}_{\mathrm{III}}\right|$ corresponding to the three terms in (3) are given in these figures, too. Additionally the experimental values $\boldsymbol{p}_{\text {exp }}$ are plotted. For selected temperatures $\boldsymbol{p}_{\text {calc }}$ is listed in Table 4.

In case of $\mathrm{CNB}$ fair agreement between the calculated and the measured pyroelectric coefficient

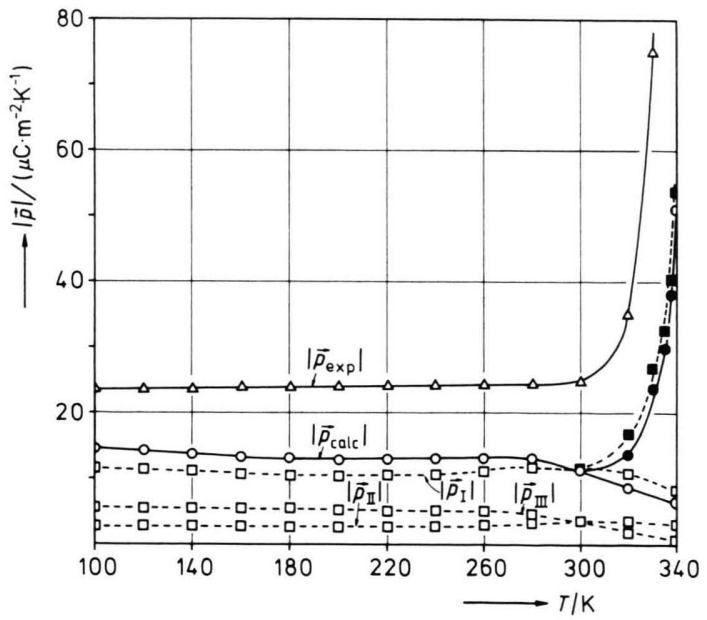

Fig. 13. Calculated pyroelectric coefficients $\left|\boldsymbol{p}_{\text {calc }}\right|(0),\left|\boldsymbol{p}_{\mathrm{I}}\right|$ $(\square),\left|p_{\text {II }}\right|(\square)$, and $\left|p_{\text {III }}\right|(\square)$, together with the measured one $\left|\boldsymbol{p}_{\exp }\right|(\Delta)$ for $1-\mathrm{CN}-4-\mathrm{Br}-\mathrm{C}_{6} \mathrm{H}_{4}$ vs. temperature. Filled symbols represent data calculated with the assumption of onset of molecular librational motions at $T>300 \mathrm{~K}$. 
is found, while for NBN the misfit is substantial. The fact is, that in both cases the accuracy of $\boldsymbol{\mu}$ and $\left\langle\boldsymbol{E}_{\mathrm{N}}\right\rangle$ is not better than 20\% [6]. By chance the uncertainties in $\boldsymbol{\mu}(\mathrm{CNB})$ and $\left\langle\boldsymbol{E}_{\mathrm{N}}\right\rangle(\mathrm{CNB})$ cancel each other, but they accumulate for NBN. The third term in (3), $\boldsymbol{p}_{\mathrm{III}}$, is mainly due to the difference in $\boldsymbol{\mu}$ and $\left\langle\boldsymbol{E}_{\mathrm{N}}\right\rangle$. It is obvious that the uncertainties in $\boldsymbol{\mu}$ and $\left\langle\boldsymbol{E}_{\mathrm{N}}\right\rangle$ multiply in $\boldsymbol{p}_{\mathrm{III}}$. An empirical value of $1.4 \cdot\left\langle\boldsymbol{E}_{\mathrm{N}}\right\rangle(\mathrm{NBN})$ leads to $\mid \boldsymbol{p}_{\text {calc, 2 }}$, which fits the experimental curve satisfactory. Despite of this, both values $\boldsymbol{\mu} \mid(\mathrm{NBN})$ and $1.4 \cdot\left|\left\langle\boldsymbol{E}_{\mathrm{N}}\right\rangle\right|(\mathrm{NBN})$ resulting from the calculated charge distribution, show still much to high values. It can be seen that uncertainties introduced by the quantum chemical calculations affect the model used to calculate $\boldsymbol{p}=f(T)$ heavily if $\boldsymbol{\mu}$ and $\left\langle\boldsymbol{E}_{\mathrm{N}}\right\rangle$ are influenced in a different way.

For BBN the angular variation of the polarization $\boldsymbol{P}$ with $T$ was calculated from

$$
\boldsymbol{P}=\int \boldsymbol{p}(T) \mathrm{d} T,
$$

using the measured pyroelectric coefficient and $\boldsymbol{P}=0 \mu \mathrm{C} \mathrm{m}^{-2} \mathrm{~K}^{-1}$ for $T>T_{\mathrm{c}}$ as starting point for the integration. Thereby we assume that the phase transition leads to a non polar structure. The direction of the polarization, $\boldsymbol{P}(\mathrm{BBN})$, is not fixed along a crystal axis but can point in any direction within the $a c$-plane. The direction of $\boldsymbol{P}(\mathrm{BBN})$ must be known for a proper estimate of $\varepsilon_{\mathrm{P}}=f(T, \theta)$ from the measured values. Furthermore the changes of $\delta$ and $\beta$ with temperature are deduced directly from the angular variation of $\boldsymbol{P}=f(T)$, assuming $\boldsymbol{\mu}$ and $\left\langle\boldsymbol{E}_{\mathrm{N}}\right\rangle$ to be constant over the whole temperature range. Therefore (4) and (5) are not needed for the calculations.

$\boldsymbol{p}_{\text {calc }}(\mathrm{BBN})=f(T)$ and $\boldsymbol{p}_{\exp }(\mathrm{BBN})$ are shown in Fig. 13 together with the components $\left|\boldsymbol{p}_{\mathrm{I}}\right|,\left|\boldsymbol{p}_{\mathrm{II}}\right|$, and $\boldsymbol{p}_{\mathrm{III}}$. The latter ones correspond to the appropriate terms in (3). $\left|\boldsymbol{p}_{\text {calc }}\right|$ turnes out to be considerably smaller than $\left|\boldsymbol{p}_{\exp }\right|$. However the practical independence of $\mid \boldsymbol{p}_{\text {exp }}$ from temperature is reflected by $\boldsymbol{p}_{\text {calc }} \mid$ in the temperature range $100 \leqq T / \mathrm{K} \leqq 300$. Selected values of $\left|\boldsymbol{p}_{\text {calc }}\right|=f(T)$ are given in Table 4 .
The very strong increase of $\boldsymbol{p}_{\exp }$ near $T_{\mathrm{c}}$ can not be explained in the light of $\varepsilon(T)=f(T), \delta(T)=$ $f(T)$, and $\beta(T)=f(T)$, but it can be interpreted by taking the molecular processes at $T_{\mathrm{c}}$ into account. A schematic display of the crystal structure of BBN [4] is shown in Figure 9. The possibility that molecular librational motions increase with increasing temperature has to be considered. For example, a change of the mean molecular direction due to librational motions about the axis [010] is equivalent to a change in the direction of the dipole moment. Due to the variation of $\cos \delta$, where $\delta=\Varangle(\boldsymbol{\mu}, \boldsymbol{P})$, this would affect the first term in (3). So a structural change directly gives rise to a change in the pyroelectric coefficient.

The curves represented by filled symbols in Fig. 13 are calculated using a change in direction of $\boldsymbol{\mu}$ from $\varphi=207^{\circ}$ to $\varphi=203^{\circ}$ in the temperature range $320 \leqq T / \mathrm{K} \leqq 340$. Thereby the assumption was made that $\mathrm{d} \delta / \mathrm{d} T$ increases with $T \rightarrow T_{\mathrm{c}}$. In this way the increase of the measured pyroelectric coefficient can be interpreted as an increase of molecular librational motions about the axis [010], leading to a change of the mean direction of the dipole moments.

On the other hand librational motions about the axis perpendicular to the molecule plane are possible. A setting in of an order-disorder mechanism at about $T_{\mathrm{c}}$ due to a $180^{\circ}$ flip about this axis is thinkable. Such a mechanism would lead to a decrease of the averaged value of $\mid \boldsymbol{\mu}$ and $\mid\left\langle\boldsymbol{E}_{\mathrm{N}}\right\rangle$ and therefore to a decrease of $\left|\boldsymbol{p}_{\mathrm{I}}\right|$ and $\left|\boldsymbol{p}_{\mathrm{II}}\right|$ in (3). Therefore the $180^{\circ}$ flip of the molecules about an axis perpendicular to the molecule plane might be an explanation for the decrease of $\left|\boldsymbol{p}_{\exp }\right|$ for $T>T_{\mathrm{c}}$.

\section{Acknowledgement}

We are grateful to the Stiftung Volkswagenwerk for support of this work. 
[1] T. Asaji and Al. Weiss, Z. Naturforsch. 40a, 567 (1985).

[2] S. Sharma, H. Paulus, N. Weiden, and Al. Weiss, Z. Kristallogr. 171, 101 (1985).

[3] T. Higashi and K. Osaki, Acta Crystallogr. B 33, 2337 (1977).

[4] D. Britton, J. Konnert, and S. Lam, Cryst. Struct. Comm. 6, 45 (1977).

[5] D. Berlincourt, W. R. Cook, and M. E. Rander, Acta Crystallogr. 16, 163 (1963).

[6] S. Fleck, M. C. Böhm, and Al. Weiss, Z. Naturforsch. 42 a, 57 (1987).

[7] S. Fleck and Al. Weiss, Z. Naturforsch. 41 a, 1289 (1986).

[8] J. F. Nye, Physical Properties of Crystals. Clarendon Press, Oxford 1957.
[9] S. B. Hendricks, Z. Kristallogr. 84, 85 (1933).

[10] A. Klug, Nature London 160, 570 (1947).

[11] C. Dean, J. Chem. Phys. 23, 1734 (1955).

[12] A. L. McClellan, Tables of Experimental Dipole Moments. Freeman, San Francisco 1963.

[13] F. J. Mopsik and M. G. Broadhurst, J. Appl. Phys. 46, 4202 (1975)

[14] N. Le Calve, F. Romain, and B. Pasquier, J. Raman Spectrosc. 8, 239 (1979).

[15] C. Pigenet, N. Le Calve, and B. Pasquier, J. Raman Spectrosc. 9, 393 (1980).

[16] C. Pigenet, N. Le Calve, and B. Pasquier, J. Mol. Struct. 61, 183 (1980). 